\title{
E se Nossa Oficina não Der Certo?
}

\author{
Estéfane C. Souza $^{1}$, Diego C. Silva ${ }^{1}$, Roberto A. Bittencourt ${ }^{1}$ \\ ${ }^{1}$ UEFS - Universidade Estadual de Feira de Santana \\ Av. Transnordestina, s/n, Novo Horizonte \\ Feira de Santana - BA, Brasil - 44036-900 \\ \{estefanescs, diego.cs282\}@gmail.com, roberto@uefs.br
}

\begin{abstract}
Adding computing education in the compulsory school system is a theme of growing interest in Brazil. Creative Computing is one approach to work with computing concepts that privileges creativity and collaboration. This paper presents an experience report of a Creative Computing workshop with a sixth grade class of a public state middle school, supported by the use of the Scratch environment and a textbook. The experience allowed to identify factors that may influence either positively or negatively in both students' effective learning and their motivation.
\end{abstract}

Resumo. A inclusão do ensino de computação na educação básica é uma tema de interesse crescente no Brasil. Uma das formas de trabalhar conceitos de computação é através da Computação Criativa, abordagem que privilegia a criatividade e a colaboração. Este artigo apresenta um relato de experiência de uma oficina de Computação Criativa com uma turma de sexto ano do Ensino Fundamental II de uma escola estadual pública, apoiada pelo uso do ambiente Scratch e de um livro didático. A experiência permitiu identificar fatores que podem influenciar positiva ou negativamente na efetiva aprendizagem e no nível de motivação dos estudantes.

\section{Introdução}

O contato com o computador para fins educativos permite desenvolver habilidades intelectuais, sociais, culturais e motoras nos estudantes [Bueno e Ritzel 2013]. Através do ensino de programação e do pensamento computacional, inúmeras habilidades podem ser desenvolvidas pelo indivíduo, como desenvolvimento cognitivo, capacidade de resolução de problemas, raciocínio lógico e abstração, consideradas fundamentais para a formação básica [Rodrigues et al. 2015].

Em todo o mundo, há a preocupação em oferecer o ensino de computação na Educação Básica, pois este aborda vários conceitos e habilidades importantes para o desenvolvimento dos alunos no século XXI [Dantas 2017]. Neste contexto, várias entidades trabalham no desenvolvimento de diretrizes, elaboração de currículos e na definição do sequenciamento de conteúdos a serem introduzidos no ensino da computação [Alves et al. 2019].

Países como Austrália e Inglaterra já inseriram o ensino da computação no currículo da Educação Básica. No Brasil, devido à falta de um currículo nacional que demande o ensino de computação, o acesso dos estudantes a este conhecimento normalmente ocorre por meio de atividades extracurriculares [Monte-Alto et al. 2017]. 
Assim, o cenário brasileiro fica restrito a iniciativas de cursos e oficinas extracurriculares [Costa et al. 2012].

A transversalidade da computação faz dela uma ciência que pode ser alinhada a qualquer um dos eixos do conhecimento tradicionais. Para direcionar essa abordagem, a Sociedade Brasileira de Computação criou as Diretrizes para Ensino de Computação na Educação Básica [SBC 2017]. Esse documento trata das competências e habilidades que devem ser trabalhadas através do ensino de computação nas escolas do ensino fundamental até o ensino médio. Nas diretrizes, o ensino de computação é pautado sobre três eixos: Pensamento Computacional, Mundo Digital e Cultura Digital.

O número de trabalhos sobre o ensino de computação na educação básica e de relatos de experiência associados vem aumentando consistentemente [Santos et al. 2018]. Entretanto, a maioria destas narrações são acerca de situações de êxito. Contudo, existem casos em que há circunstâncias internas e externas que não são propícias nas escolas, e a literatura carece de publicações mostrando esta realidade que interfere diretamente na ação. Em essência, faltam trabalhos mostrando também os projetos que deram errado. Este trabalho procura suprir esta lacuna descrevendo uma oficina de computação criativa que enfrentou vários problemas em sua execução, procurando destacar as lições aprendidas com a experiência.

Originalmente, o objetivo principal da oficina ofertada era permitir que os estudantes do $6^{\circ}$ ano do Ensino Fundamental II de uma escola pública estadual aprendessem sobre conceitos básicos da computação, através da aplicação dos conteúdos presentes no livro Computação e Eu [Santana et al. 2019a], especialmente os baseados em Computação Criativa. Este artigo objetiva descrever, através do relato da experiência, que nem sempre o planejamento de uma oficina de computação funciona como o esperado, permitindo entender e refletir sobre aspectos que devem ser melhorados a fim de que as falhas percebidas são sejam repetidas em trabalhos futuros.

\section{Fundamentação Teórica}

Pensamento Computacional (PC) é percebido por pesquisadores como uma das habilidades fundamentais do ser humano, tão importante quanto leitura, escrita e aritmética, por servir para descrever, representar e explicar o mundo e os seus processos [SBC 2017]. PC é um dos eixos das diretrizes da SBC para a computação na educação básica. Segundo Cuny, Snyder e Wing (2010), PC é o processo envolvido em organizar problemas e formular soluções de modo que elas possam ser representadas e realizadas por um agente de processamento de informação, comumente, um computador. Essa formulação passa pelos processos de análise, abstração e automação. Além do PC, nas diretrizes da SBC, há dois eixos adicionais [SBC 2017]: Mundo Digital, para compreender melhor o mundo contemporâneo, e Cultura Digital, para o letramento em tecnologias do mundo digital.

Além dos eixos citados, as diretrizes da SBC elencam cinco competências específicas que podem ser desenvolvidas com o ensino de computação na educação básica. Estas competências são: compreensão e transformação do mundo; aplicação de computação em diversas áreas; formulação, execução e análise do processo de resolução de problemas; desenvolvimento de projetos envolvendo Computação; e compreensão 
dos princípios de Ciência da Computação. Essas habilidades são relacionadas a outras aptidões gerais da Base Nacional Comum Curricular (BNCC) [SBC 2017].

Computação Criativa é uma abordagem de ensino-aprendizagem de computação para a educação básica que procura destacar a criatividade dos estudantes na expressão de suas ideias através do computador [Brennan et al. 2011]. Desenvolvida em Harvard e com cooperação dos criadores do Scratch do MIT, os autores criaram um currículo e materiais didáticos para a implementação desta abordagem em sala de aula.

A computação criativa baseia-se na criatividade, imaginação e interesses, apoiando o desenvolvimento de ligações pessoais com a computação. Objetiva o desenvolvimento dos estudantes como pensadores computacionais, indivíduos capazes de recorrer a conceitos e práticas computacionais em todos os aspectos das suas vidas, e não apenas prepará-los para carreiras da área da computação. Além disso, enfatiza os conhecimentos que os jovens precisam para criar meios computacionais interativos similares aos que desfrutam no seu dia-a-dia [Brennan et al. 2011].

Pensar criativamente e criar soluções inovadoras são habilidades importantes para o século XXI. A abordagem tradicional de aprendizagem no jardim de infância, baseada em pensar criativamente, trabalha o Pensamento Espiral Criativo, em que as crianças "imaginam o que querem fazer, criam um projeto baseado em suas ideias, brincam com suas criações, compartilham suas criações com outras pessoas e refletem sobre suas experiências, o que as leva a imaginar novas ideias e novos projetos" [Resnick 2007]. Esta abordagem também pode ser utilizada através das tecnologias digitais de modo que estudantes de todas as idades continuem a se desenvolver como pensadores criativos. Umas das ferramentas capazes de estender a abordagem do jardim de infância para os contextos digitais é o ambiente Scratch.

As atividades relacionadas à computação criativa podem trabalhar conceitos de pensamento computacional, de práticas de computação e de perspectivas em relação ao mundo. Alguns destes conceitos, práticas e perspectivas são: sequência, loops, paralelismo, eventos, condicionais, operadores, iterar, testar, depurar, remixar, abstrair, modularizar, expressar-se criativamente, dentre outros [Brennan et al. 2011].

\subsection{Trabalhos Relacionados}

Um mapeamento sistemático sobre Pensamento Computacional e Programação foi realizado por Santos et al. (2018), onde os autores analisaram 338 estudos publicados entre 2001 e 2016. Os autores elaboraram um esquema para classificar o tipo de estudo, a modalidade da educação básica, contexto metodológico, ferramentas e linguagens utilizadas em cada trabalho. A maioria dos artigos são relatos de experiência, nos quais os contextos metodológicos mais utilizados são Jogos e Robótica, e as ferramentas mais usadas são o ambiente Scratch, robôs Lego e linguagens de blocos. Os autores puderam observar um crescimento significativo de estudos sobre a área do Pensamento Computacional e Programação.

Bordini et al. (2016) mapearam 62 artigos sobre a área de computação na Educação Básica no Brasil publicados durante 2010 a 2015. Destes, 42\% foram trabalhados no ensino fundamental e $42 \%$, no ensino médio. As estratégias de ensino aplicadas nos artigos analisados foram: algoritmos e programação, robótica, jogos digitais, computação desplugada, teatro/música e ensino híbrido. As ferramentas mais 
utilizadas foram Scratch e atividades desplugadas. A grande maioria dos artigos "trabalham apenas os conceitos e conteúdos da ciência da computação, e poucos integram outras disciplinas que fazem parte do currículo básico escolar. A colaboração também é outro aspecto pouco explorado, sendo abordada pela maioria dos trabalhos apenas como execução de tarefas em grupos" [Bordini et al. 2016].

Uma experiência em duas escolas do Pará com alunos do Ensino Fundamental II foi relatada por Bezerra e Dias (2012). Nestas oficinas de introdução a programação, foram utilizadas a linguagem Logo, através da ferramenta Kturtle, e o ambiente Scratch. $\mathrm{O}$ objetivo foi avaliar o impacto da experiência nas disciplinas de matemática e português. Assim como no caso relatado no presente artigo, foram encontradas dificuldades na realização do projeto, incluindo problemas de locomoção dos estudantes, baixa adesão, espaçamento entre aulas e outros fatores externos. Ao final da oficina, foi possível constatar um aumento da motivação e concentração.

Um curso de computação criativa com carga horária de 30 horas, baseado nos materiais da Universidade de Harvard [Brennan et al. 2011], foi realizado com alunos do $8^{\circ}$ e $9^{\circ}$ ano do ensino fundamental de uma escola pública municipal de Piritiba, Bahia, no ano de 2018 [Santos et al. 2019]. Para avaliação, os autores aplicaram dois questionários, um para caracterizar os participantes e outro para avaliar suas atitudes. Os resultados mostraram que a maioria dos alunos passaram a achar a computação interessante por causa do curso e que desejavam participar de mais atividades que envolvam esta área de conhecimento. Diferente deste trabalho, o presente artigo utiliza uma proposta particular do ensino da computação criativa na Educação Básica através do uso do livro Computação e Eu [Santana et al. 2019a]. Assim como eles, as atividades foram realizadas por meio do ambiente lúdico Scratch.

Mesmo com os trabalhos descritos nesta seção, é importante frisar que ainda há poucas experiências descritas em profundidade sobre o ensino de computação através de uma abordagem de computação criativa no ensino fundamental brasileiro.

\section{Metodologia}

Nesta seção, são descritos a abordagem de Computação Criativa, os participantes da oficina e o planejamento da oficina.

\subsection{Abordagem de Ensino-Aprendizagem}

As atividades trabalhadas nas oficinas foram selecionadas do livro Computação e Eu [Santana et al. 2019a]. As aulas selecionadas, de acordo com os autores do livro, foram inspiradas no currículo Creative Computing de Brennan, no qual os aprendizes são motivados a se expressarem artisticamente através de criação de animações e, paralelamente, aprendem conceitos de programação [Santana et al. 2019a].

A abordagem de ensino-aprendizagem usada foi a monitoria ativa. Nela, os estudantes recebem desafios e atividades que devem ser realizados através da descoberta e da criatividade. Os tutores estão a todo momento disponíveis para o esclarecimento de dúvidas e auxiliam os estudantes no processo de aprendizagem, buscando despertar o interesse pelas atividades realizadas e a ajudá-los a pensar criativamente. 


\subsection{Participantes}

Nesta oficina, participaram 20 estudantes do $6^{\circ}$ ano do ensino fundamental de uma escola estadual de tempo integral do município de Feira de Santana, formando apenas uma turma. Dos 20 participantes, 7 eram meninas e 13 eram meninos. A idade variava de 11 a 17 anos. Nenhum participante relatou já conhecer a ferramenta Scratch. Porém, a maioria deles afirmou achar a computação interessante.

\subsection{Planejamento da Oficina}

A oficina foi programada para uma carga horária de 10 horas, realizada em cinco aulas com a duração de duas horas, com um encontro por semana. A oficina foi realizada no turno vespertino no período de 11 de setembro a 18 de outubro de 2019 . A oficina foi mediada por dois tutores, ambos graduandos do curso de Engenharia de Computação da Universidade Estadual de Feira de Santana (UEFS).

O planejamento da oficina, contendo os objetivos, a atividades realizadas nas aulas e o conteúdo trabalhado, é descrito na Tabela 3.3.

\section{Tabela 1: Planejamento da oficina}

\begin{tabular}{|c|c|c|c|}
\hline Aula & Objetivos & Atividades & Conteúdos \\
\hline 1 & $\begin{array}{l}\text { Criar algoritmos simples } \\
\text { utilizando uma lista específica de } \\
\text { comandos. Resolver problemas } \\
\text { simples envolvendo sequências } \\
\text { de passos e repetição. }\end{array}$ & $\begin{array}{l}\text { Tutorial Labirinto - } \\
\text { Sequências (Tutorial } \\
\text { Hora do Código). } \\
\text { Tutorial Abelha }- \text { Laços } \\
\text { (Tutorial Hora do } \\
\text { Código). }\end{array}$ & $\begin{array}{l}\text { Fluxo de execução de um } \\
\text { programa } \\
\text { Comandos direcionais (siga } \\
\text { em frente, vire à direita, vire à } \\
\text { esquerda); Comandos de } \\
\text { repetição (Repita .. Vezes). }\end{array}$ \\
\hline 2 & $\begin{array}{l}\text { Conhecer o ambiente Scratch e } \\
\text { exercitar a imaginação para a } \\
\text { criação de projetos. }\end{array}$ & $\begin{array}{l}\text { Criar animações livres no } \\
\text { Scratch. }\end{array}$ & $\begin{array}{l}\text { Ambiente de programação } \\
\text { Scratch. }\end{array}$ \\
\hline 3 & $\begin{array}{l}\text { Criar uma representação de seus } \\
\text { interesses pessoais utilizando o } \\
\text { Scratch e familiarizar-se com } \\
\text { outros comandos do Scratch. }\end{array}$ & $\begin{array}{l}\text { O que eu quero ser no } \\
\text { futuro. }\end{array}$ & $\begin{array}{l}\text { Sequência, estruturas de } \\
\text { repetição e condicionais } \\
\text { (Comandos de movimento, } \\
\text { aparência, controle e eventos). }\end{array}$ \\
\hline 4 & $\begin{array}{l}\text { Encontrar comandos específicos } \\
\text { no Scratch e criar um programa } \\
\text { simples a partir de uma lista } \\
\text { definida de blocos. }\end{array}$ & $\begin{array}{l}\text { Desafio dos } 5 \text { blocos. } \\
\text { Desafio dos } 10 \text { blocos. }\end{array}$ & $\begin{array}{l}\text { Sequência, estruturas de } \\
\text { repetição e condicionais } \\
\text { (Comandos de movimento, } \\
\text { aparência, controle e eventos). }\end{array}$ \\
\hline 5 & $\begin{array}{l}\text { Utilizar blocos de eventos para } \\
\text { interagir com as formas e blocos } \\
\text { de sons. Aplicar conhecimentos } \\
\text { de loops para os eventos. } \\
\text { Compreender o uso de eventos } \\
\text { paralelos. }\end{array}$ & Construindo uma banda. & $\begin{array}{l}\text { Sequência, Estruturas de } \\
\text { repetição e paralelismo, } \\
\text { (Comandos de eventos, som, } \\
\text { controle). }\end{array}$ \\
\hline
\end{tabular}

A primeira aula é voltada a realização de tutoriais com listas de comandos específicos, a fim de que os participantes familiarizem-se com programação em blocos, similares à linguagem Scratch. Esta aula auxilia no desenvolvimento do raciocínio lógico, já que os aprendizes devem pensar na ordem em que os blocos devem ser 
encaixados para passar de fase nos tutoriais. Os conteúdos trabalhados são sequência, comandos direcionais e estrutura de repetição.

A segunda aula é uma apresentação do ambiente Scratch e das possibilidades de projetos que podem ser criados com ele. Nesta aula, os aprendizes são convidados a explorar todas as abas do Scratch para conhecê-lo e a criar uma animação livre com quaisquer blocos. A animação livre objetiva despertar a criatividade e a imaginação dos estudantes. Não há um conteúdo abordado exclusivamente na aula, já que é livre a escolha dos comandos a serem utilizados.

Na terceira aula, são abordados algoritmos em sequência, estruturas de repetição e condicionais, utilizando os comandos de movimento, aparência, controle e eventos. A aula é dedicada à criação de uma animação sobre o que eles desejam ser no futuro, e são apresentados alguns comandos que podem ser utilizados. Esta aula estimula os participantes a pensarem no que eles gostam e a criar projetos multimídia.

$\mathrm{Na}$ quarta aula, os aprendizes devem criar duas animações em Scratch utilizando apenas um conjunto de blocos específicos predefinidos. A primeira animação será feita com cinco blocos e a segunda, com 10 blocos, onde um bloco deve ser usado pelo menos uma vez. A partir daí, os participantes podem perceber que, utilizando um pequeno conjunto de instruções, é possível realizar tarefas diferentes, além de notar que a repetição destas instruções afeta o resultado.

A quinta aula é direcionada à criação do projeto de uma banda. Após a criação do projeto, os aprendizes apresentarão sua banda aos colegas. Este projeto trabalha a oralidade dos estudantes. Nesta aula, os participantes podem utilizar todos os conceitos aprendidos nas aulas anteriores, além de aprenderem o conceito de paralelismo.

\section{Nossa Experiência}

Nesta seção, apresentamos nossas percepções a partir das observações realizadas, relatando também as principais dificuldades encontradas pelos participantes.

No primeiro dia, no Tutorial do Labirinto do Code.org, como os participantes não conheciam linguagens de blocos, alguns tiveram dificuldade em compreender como arrastar os blocos para a área de comando. Além disso, as principais dificuldades eram entender qual comando direcional utilizar, direita ou esquerda, e a quantidade de passos necessários para mover o pássaro. Todos conseguiram realizar essa atividade.

No Tutorial da Abelha, a dificuldade em desenvolver a lógica para alcançar o objetivo reduziu-se. Apesar de explicarmos o funcionamento das estruturas de repetição e em insistir para que fossem utilizadas, os estudantes optaram por utilizar comandos de sequência. A dispersão da turma aumentou e apenas uma minoria conseguiu concluir.

No segundo dia, devido às dificuldades na aula anterior, foi necessário, antes de apresentar o conteúdo da aula, realizar uma atividade desplugada semelhante ao tutorial do labirinto, pedindo que os estudantes indicassem a sequência de passos que deveria ser realizada pelo passarinho para chegar até o porco. Para estimulá-los, dissemos que a cada acerto, eles ganhariam um ponto e que, ao término da oficina, os pontos seriam convertidos em uma premiação. Ao final da atividade, percebeu-se que os aprendizes compreenderam melhor os comandos direcionais e a utilização de repetição. 
Continuando o segundo dia, apesar de os participantes não conhecerem Scratch, se mostraram animados durante a apresentação do ambiente. A dúvida mais recorrente na criação da animação livre era como executar o projeto, pois não utilizavam os comandos de eventos como o primeiro bloco. Os participantes geralmente alteraram os personagens e o cenário, e utilizaram comandos de movimento e aparência. Para os mais rápidos, propusemos que adicionassem outro personagem e realizassem um diálogo entre eles. Foi perceptível, durante a criação dos projetos, que alguns realizavam a atividade sem interesse e utilizavam o chromebook para outros fins. Os tutores tentaram prender a atenção deles, mas não conseguiram. Durante a aula, duas alunas foram convocadas pela coordenadora para realizarem a confecção de roupas para um evento que aconteceria na escola e, por isso, não realizaram as atividades.

No terceiro dia, apresentamos uma animação sobre a atividade "O que eu quero ser no futuro" e, ao final, perguntamos aos participantes qual profissão a personagem da animação gostaria de ter. Todos estavam agitados. Então, foi necessário reproduzir o vídeo mais de uma vez. Em seguida, orientamos que eles criassem a animação "O que eu quero ser no futuro", apresentando alguns blocos de suporte. Nesta atividade, não houve dificuldades, exceto de um aluno que estava participando pela primeira vez. Além disso, alguns aprendizes esqueceram de utilizar blocos de eventos e controle. Umas das dificuldades enfrentadas que atrapalharam o andamento foi a constante interrupção não solicitada realizada pela bibliotecária responsável pelo ambiente de aula, informando que se algum aluno acessasse jogos ou músicas, o chromebook seria confiscado.

$\mathrm{Na}$ atividade do terceiro dia, percebemos que muitos dos participantes não sabiam qual profissão gostariam de ter. Então, houve uma certa demora para começar a criar a animação e um dos alunos realizou a animação de uma sereia, distante do que havia sido proposto. Um aprendiz desejava que a fala do personagem fosse reproduzida por áudio em vez de escrita, e um dos tutores explicou como ele poderia gravar o som. Todos os participantes utilizaram os comandos de sons.

No quarto dia, nas atividades dos desafio dos blocos, apenas seis alunos estavam presentes. Como todos haviam utilizado os blocos em aulas anteriores, nenhuma dúvida surgiu exceto as de um aluno que participava pela primeira vez. Em ambos os desafios, os participantes encaixavam os blocos de forma aleatória sem um objetivo específico, apenas com a finalidade de terminar a atividade, apesar dos incentivos a fazerem algo mais criativo. No primeiro desafio, todos concluíram a atividade. Durante o segundo desafio, os aprendizes começaram a utilizar o chromebook para outros fins. Por isso, a todo momento os tutores pediam que voltassem para a atividade. Finalmente, apenas um aluno concluiu o desafio.

No último dia, na atividade "Construindo uma banda", havia sete alunos presentes e apenas três chromebooks disponíveis. Desta forma, a turma foi divida em um trio e duas duplas para a realização da atividade, o que dificultou o andamento da atividade. Inicialmente, exibimos um projeto de exemplo e os questionamos sobre quais blocos poderiam ser utilizados. Em seguida, iniciou-se a criação dos projetos. Um dos participantes, após terminar a atividade com o seu trio, passou a auxiliar na dupla de colegas, explicando alguns comandos e como realizar determinadas ações. Após todos concluírem, dois grupos apresentaram o projeto, explicando como havia sido feito e como funcionava. 


\section{Lições Aprendidas}

As lições aprendidas com a oficina estão relacionadas com a competição e atividades desplugadas que motivam os estudantes a participar ativamente, além das interrupções, o interesse pela computação e atividades criativas que podem explicar a falta de engajamento e comprometimento.

A competição é um poderoso artifício. Realizar atividades em que os estudantes competem entre si ajudou no desempenho das atividades. A competição foi realizada na segunda aula, a partir da qual foi perceptível que os estudantes criaram os projetos com mais entusiasmo e dedicação, gerando melhor qualidade nos resultados.

Atividades desplugadas despertam o interesse e engajam os aprendizes. Estas atividades mantém os aprendizes concentrados e empenhados em participar. Por gerarem maior interação física, o estímulo acaba sendo maior e a participação, mais ativa.

Interesse pela computação. Talvez os participantes não estivessem tão interessados pela computação nesta etapa de suas vidas, embora a maioria tenha afirmado que se interessam pela área. Isto pode ter influenciado no desempenho deles nas atividades, que eram realizadas com desânimo na maior parte do tempo, por mais que os tutores tentassem motivar os estudantes.

Uso dos chromebooks. Estes dispositivos foram projetados para rodar programas através de um navegador. Assim, nosso uso de Scratch devia ocorrer através de acesso à versão em rede do ambiente. Por outro lado, os estudantes utilizavam os chromebooks frequentemente para outras finalidades, como redes sociais e músicas, o que tirava o foco das aulas e atrapalhava a realização das atividades.

Turmas mistas são difíceis. Embora todos os estudantes da turma estivessem no $6^{\circ}$ ano, eles possuíam idades variadas, de 11 a 17 anos. As atividades foram concebidas para alunos do $6^{\circ}$ ano que geralmente tem entre 11 a 12 anos. Desta forma, os temas abordados nas animações talvez não fossem interessantes para os mais velhos.

Interrupções na programação das oficinas. Por funcionar em tempo integral, a escola participante já possui uma grade definida de atividades para os alunos no turno em que a oficina foi oferecida. Desta forma, muitas vezes os participantes eram convocados durante o período da oficina para realizar outras atividades.

Interferências atrapalham o engajamento. Frequentemente, a oficina era interrompida por colaboradores da escola, atrapalhando as atividades. Uma situação que ocorria quando colaboradores da escola, principalmente a responsável pelo ambiente da biblioteca, tentavam fazer intervenções mais rígidas durante a oficina, tirando o foco dos aprendizes e desencadeando um comportamento agressivo deles em resposta.

Desenvolvimento da própria lógica. Alguns estudantes não se interessavam em desenvolver estratégias para resolução dos desafios. Às vezes, eles pediam aos tutores respostas prontas. Possivelmente, a dependência em relação a seus professores em um modelo passivo de aprendizagem faz com que eles esperem comandos todo o tempo.

Nem sempre as atividades criativas são as mais eficazes. Nas tarefas que envolviam animações livres, os estudantes não sabiam o que fazer. Por normalmente esperarem um direcionamento, ao serem incentivados a pensar de forma independente, 
demoravam para serem produtivos. Já em atividades mais direcionadas, em que a construção criativa era menos utilizada, costumavam ter desempenho melhor.

Frequência na oficina. Poucos estudantes participaram das oficinas do início ao fim. Alguns chegavam quando a atividade já estava terminando, alguns saiam antes de terminar. Houve até casos de alunos que começaram a frequentar a oficina próximo a seu término. Talvez o motivo deste comportamento seja explicado pela falta de interesse.

\section{Conclusões}

Esse artigo apresentou uma experiência da oficina de Computação Criativa realizada em uma escola pública de Feira de Santana com estudantes do $6^{\circ}$ ano do Ensino Fundamental. Os aprendizes tiveram contato com o ambiente Scratch e conceitos introdutórios de programação por meio de atividades e desafios que instigam a sua criatividade.

A partir dessa experiência, foi possível atestar que nem sempre o planejamento é suficiente para que os objetivos sejam atingidos, já que fatores como interesse do público, ambiente, rotinas e outros elementos externos podem influenciar diretamente no desempenho e na compreensão. No entanto, também foi possível descobrir aspectos que permitam melhorar as oficinas e diminuir o impacto destas condicionantes negativas.

Das descobertas, podemos destacar dois pontos para solucionar ou amenizar os problemas. O primeiro é que relacionar mais fortemente os temas das atividades com o contexto em que os estudantes estão inseridos ajudaria a manter a atenção deles. É possível ainda que algumas atividades que não surtiram efeito possam ser remodeladas de acordo com a turma para que sejam mais atraentes para os aprendizes.

Pretendemos continuar ofertando oficinas de programação utilizando o livro Computação e Eu e outros livros da coleção Computação Fundamental em escolas públicas para as séries do Ensino Fundamental II, objetivando disseminar gradualmente o conhecimento em computação em escolas da região.

\section{Agradecimentos}

Os autores agradecem à direção e aos funcionários da escola estadual participante do projeto pelo apoio e pela oportunidade de realizar a oficina. Este projeto foi apoiado pela Universidade Estadual de Feira de Santana (UEFS), por meio de bolsa de extensão.

\section{Referências}

Alves, N., von Wangenheim, C. G., Hauck, J., Borgatto, A., \& Andrade, D. (2019). Uma Análise do Sequenciamento Pedagógico no Ensino de Computação na Educação Básica. In Simpósio Brasileiro de Informática na Educação - SBIE.

Bezerra, F., \& Dias, K. (2012). Programação de Computadores no Ensino Fundamental: Experiências com Logo e Scratch em Escola Pública. Revista Traços, 14(30).

Bordini, A., Avila, C. M. O., Weisshahn, Y., da Cunha, M. M., da Costa Cavalheiro, S. A., Foss, L., Aguiar, M. S., \& Reiser, R. H. S. (2016). Computação na Educação 
Básica no Brasil: O Estado da Arte. Revista de Informática Teórica e Aplicada, 23(2): 210-238.

Brennan, K., Chung, M., \& Hawson, J. (2011). Creative Computing: A Design-Based Introduction to Computational Thinking. Acessado em Maio, 2020.

Bueno, A. P., \& Ritzel, M. I. (2013). A Informática no Contexto Educacional. Revista Conhecimento Online, 2.

Costa, T., Batista, A., Maia, M., Almeida, L., \& Farias, A. (2012). Trabalhando Fundamentos de Computação no Nível Fundamental: Experiência de Licenciandos em Computação da Universidade Federal da Paraíba. In XX Workshop de Educação em Computação - WEI. Curitiba, PR, Brasil.

Cuny, J., Snyder, L., \& Wing, J.M. (2010). Demystifying Computational Thinking for Non-Computer Scientists. Unpublished manuscript in progress.

Dantas, J. S. (2017). O Pensamento Computacional na Educação Básica: Uma Análise sob a Perspectiva do Ensino de Computação.

Monte-Alto, H. H. L. C., Schreiner, M. A., Dörr, J. B., Lisbôa, E. S., \& dos Santos Soares, J. P. R. (2017). Iniciativas para a Disseminação da Ciência da Computação na Educação Básica no Município de Palotina - Paraná. Extensão em Foco, 1(13).

Resnick, M. (2007). All I Really Need to Know (about Creative Thinking) I Learned (by Studying how Children Learn) in Kindergarten. In Proceedings of the 6th ACM SIGCHI conference on Creativity \& Cognition.

Rodrigues, R. da Silva, Andrade, W., Guerrero, D., \& Sampaio, L. (2015). Análise dos Efeitos do Pensamento Computacional nas Habilidades de Estudantes no Ensino Básico: Um Estudo sob a Perspectiva da Programação de Computadores. In Simpósio Brasileiro de Informática na Educação - SBIE.

Santana, B. L., Araújo, L. G. J., \& Bittencourt, R. A. (2019a). Computação e Eu: Livro do Professor. Feira de Santana: Edição do Autor.

Santana, B., Araújo, L. G. J., \& Bittencourt, R. A. (2019b). Computação e Eu: Uma Proposta de Educação em Computação para o Sexto Ano do Ensino Fundamental II. In WEI 2019 - XXVII Workshop sobre Educação em Computação.

Santos, J. A. M., Bittencourt, R. A., Dias, A. M., \& Santana, B. S. (2019). Pensamento Computacional para Alunos do Ensino Fundamental de Escolas Públicas em uma Cidade de Pequeno Porte: Um Relato e Análise de Experiência. In WIE 2019 - XXV Workshop de Informática na Escola.

Santos, P. S., Araujo, L. G. J., \& Bittencourt, R. A. (2018). A Mapping Study of Computational Thinking and Programming in Brazilian K-12 Education. In FIE 2018 - 48th Annual Frontiers In Education Conference.

SBC(2017) Referenciais de Formação em Computação: Educação Básica http://www.sbc.org.br/files/ComputacaoEducacaoBasica-versaofinal-julho2017.pdf. 